\title{
ERRATA
}

VOLUME 72 EDIÇÃO 1 - Jan/Fev 2006

Expressão de glicoesfingolipídeos no carcinoma espinocelular do trato aerodigestivo superior

Glycosphingolipid expression in squamous cell carcinoma of the upper aerodigestive tract

Marcilio Ferreira Marques Filho $\bullet$ Fernando Walder

- Helio K. Takahashi • Luciana L. Guimarães • Ameria K.

Tanaka • Onivaldo Cervantes • Anita H. Straus

Correção das legendas das imagens

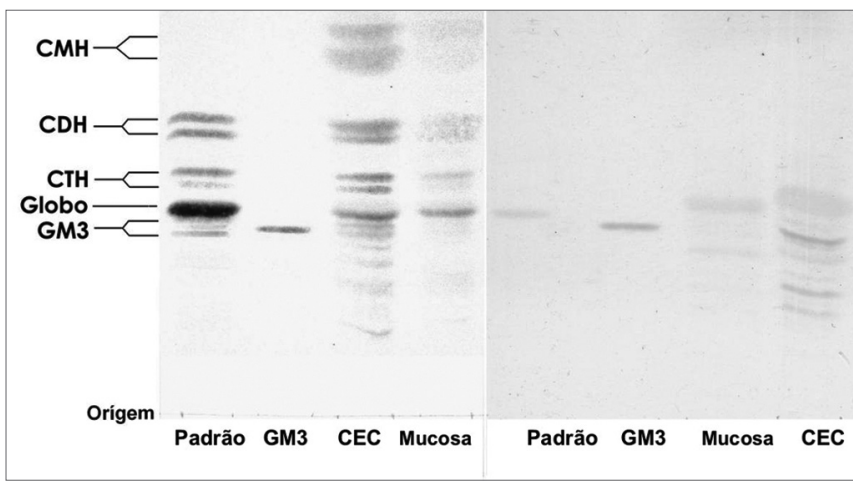

Figura 1. Lâmina de HPTLC corada com orcinol/H2SO4. (esquerda) e (direita) HPTLC corada com resorcinol. Padrão - Padrão de GSLs de eritrócitos. GM3 - Padrão de GM3 (Sigma $\left.{ }^{\circledR}\right)$. CEC - GSLs do CEC. Mucosa - GSLs da mucosa normal.

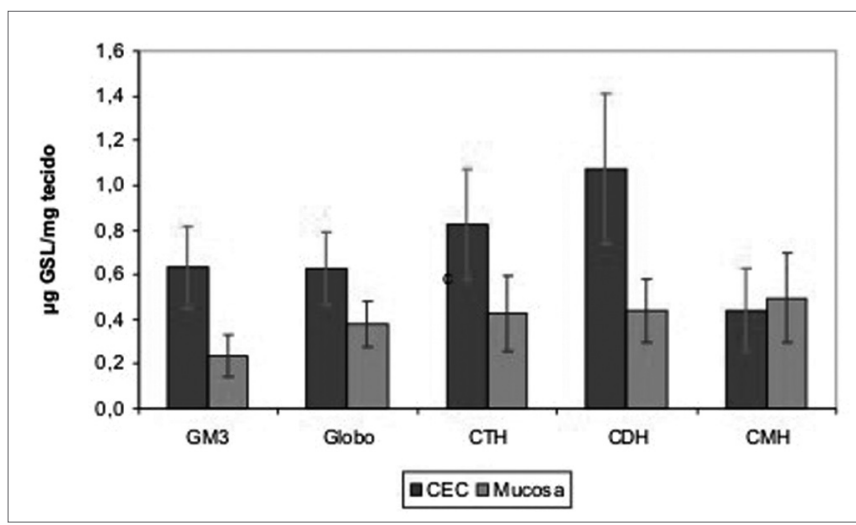

Gráfico 1. Média da quantidade de GSL no CEC e mucosa do trato aerodigestivo superior

Tabela 1. Relação entre as quantidades médias de GSL totais no CEC em relação a mucosa normal do trato aerodigestivo superior

\begin{tabular}{cccc}
\hline Estatísticas & $\begin{array}{c}\mathrm{CEC} \\
\mu \mathrm{g} \mathrm{GSL} / \mathrm{mg} \\
\text { Tecido }\end{array}$ & $\begin{array}{c}\text { Mucosa } \\
\mu \mathrm{g} \mathrm{GSL} / \mathrm{mg} \\
\text { Tecido }\end{array}$ & Teste t $(\mathrm{p})$ \\
\hline Média & 3,57 & 1,92 & \\
Desvio-padrão & 2,35 & 1,54 & 0,001 * \\
$\mathrm{n}$ & 33 & 33 & \\
\hline
\end{tabular}

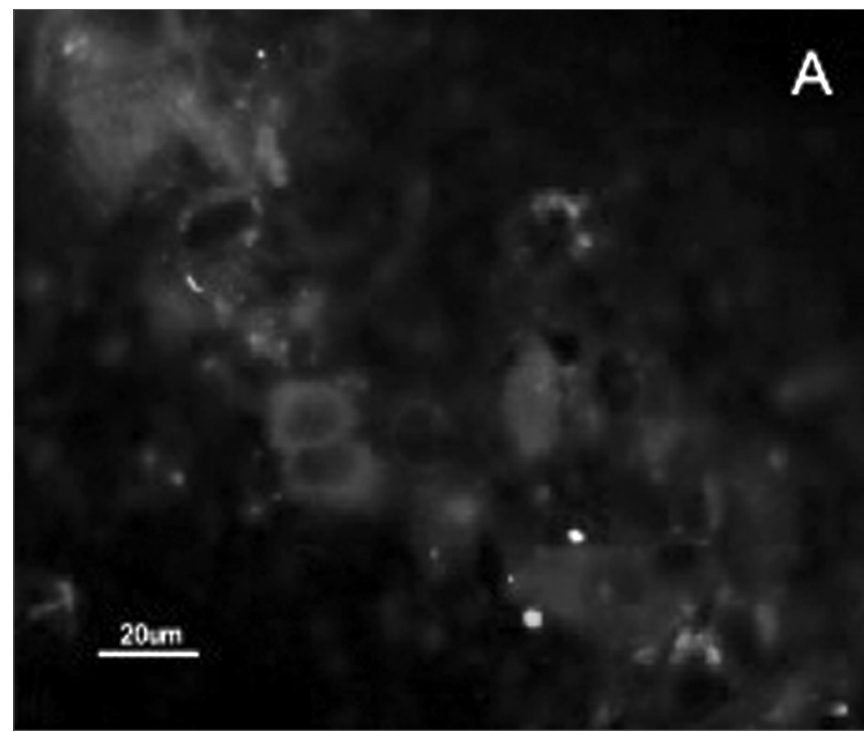

\section{Figura 2a.}

\section{Figura 2b.}

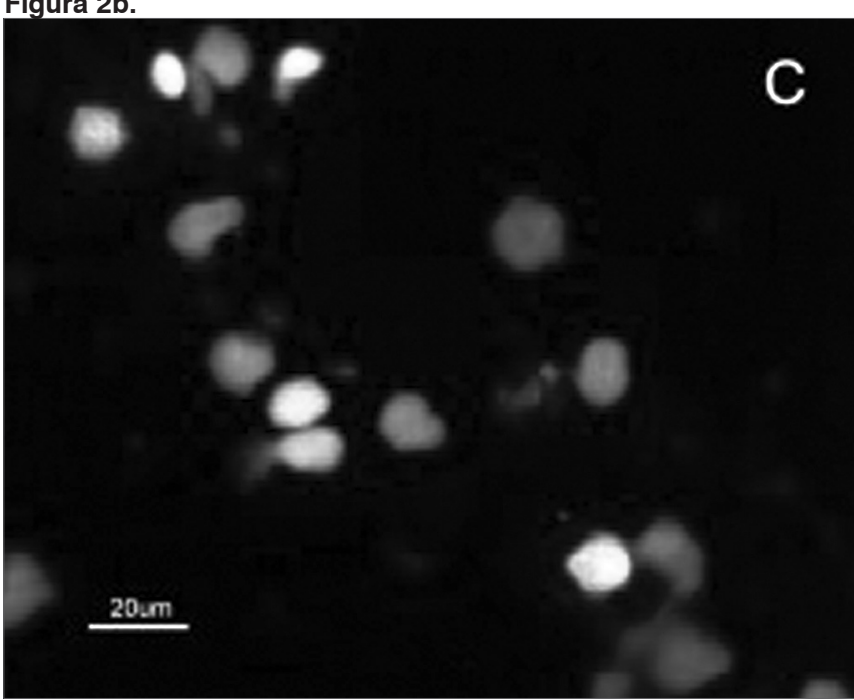

\section{Figura 2c.}




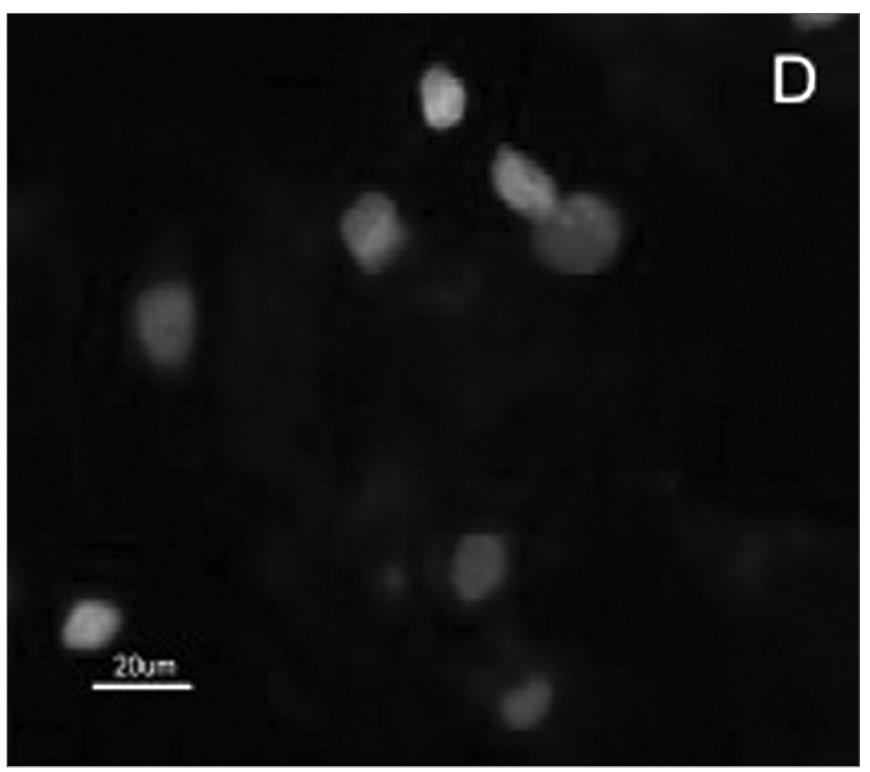

Figura 2d.

Figura 2. Fotomicrografia de imunofluorecencia indireta onde percebese a diferença de reatividade das células de CEC em comparação com as células da mucosa normal ao MoAb DH2 (AntiGM3).

A. células de CEC imunocoradas com DH2 (verde).

B. células da mucosa normal marcadas com DH2 (verde).

C. núcleo das células de CEC coradas com DAPI (azul).

D. núcleo das células da mucosa normal coradas com DAPI (azul).

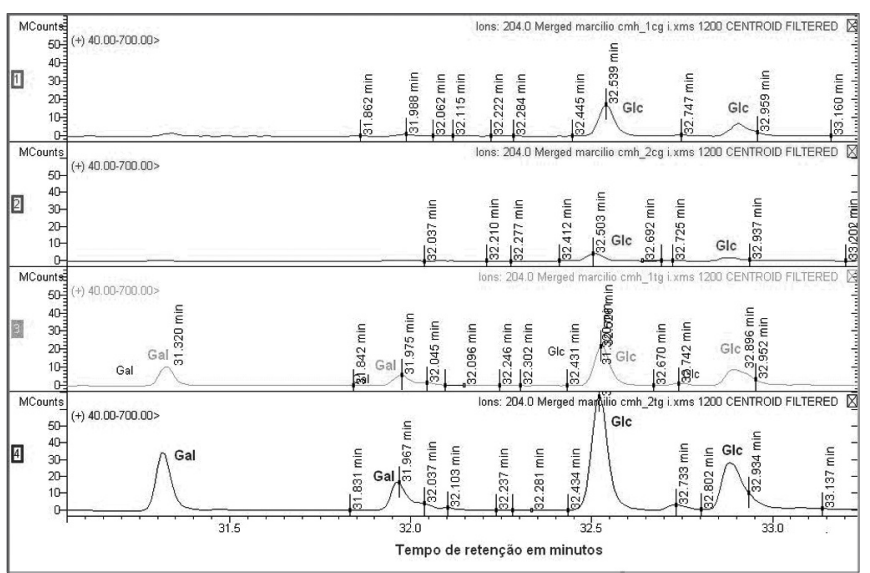

Figura 3. Espectometria de massa dos $\mathrm{CMHs}$.

Os traçados superiores ( $\mathrm{A}$ e B) mostram a identificação dos resíduos de açúcar da fração do $\mathrm{CMH}$ da mucosa do trato aerodigestivo superior. Os traçados $\mathrm{C}$ e D correspondem a identificação dos resíduos de açúcar da fração CMH do CEC.

Gal - galactose, Glc - glucose

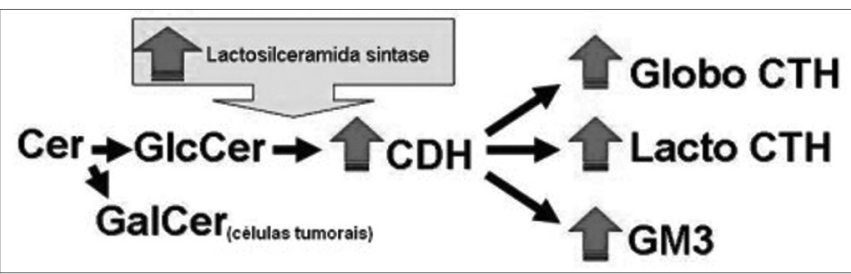

Figura 4. Esquema proposto da via de síntese dos gangliosídeos para explicar o aumento da expressão de GSLs no CEC do trato aerodigestivo superior. A maior atividade da lactosilceramida sintase aumentaria a expressão do GM3, CTH e CDH e consequentemente reduziria a oferta de Glc para síntese do GlcCer necessitando as células do CEC utilizar Gal para produzir GalCer e manter a estrutura da membrana celular.

\section{VOLUME 72 EDIÇÃO 4 - Jul/Ago 2006}

Distonia laríngea de adução: proposta e avaliação de protocolo de nasofibrolaringoscopia

Adduction laryngeal dystonia: proposal and evaluation of nasofibroscopy

Noemi Grigoletto De Biase - Paula Lorenzon $\bullet$ Mariana Dantas Aumond Lebl • Marina Padovani • Ingrid Gielow • Glaucya

Madazio • Miriam Moraes

Correção da titulação da autora Miriam Moraes.
${ }^{7}$ Fonoaudióloga especializanda em voz pelo CEV - Centro de Estudos da Voz. Fonoaudióloga colaboradora do Setor de Laringe e Voz. 